\title{
Receptor-mediated gene delivery by folic acid-modified stearic acid-grafted chitosan micelles
}

This article was published in the following Dove Press journal:

International Journal of Nanomedicine

29 July 2011

Number of times this article has been viewed

\author{
Yong-Zhong Du' \\ Li-Li Cai' \\ Jin $\mathrm{Li}^{\prime}$ \\ Meng-Dan Zhao ${ }^{2}$ \\ Feng-Ying Chen ${ }^{2}$ \\ Hong Yuan' \\ Fu-Qiang $\mathrm{Hu}^{\prime}$
}

'College of Pharmaceutical Sciences, ${ }^{2}$ Women's Hospital,

School of Medicine,

Zhejiang University, Hangzhou,

People's Republic of China
Correspondence: Fu-Qiang Hu

College of Pharmaceutical Sciences,

Zhejiang University,

866 Yuhangtang Road,

Hangzhou 310058, People's

Republic of China

$\mathrm{Tel}+8657 \mid 88208439$

Fax +86 57I 88208439

Email hufq@zju.edu.cn
Background: Cationic polymers have been accepted as effective nonviral vectors for gene delivery with low immunogenicity unlike viral vectors. However, the lack of organ or cell specificity sometimes hampers their application and the modification of polymeric vectors has also shown successful improvements in achieving cell-specific targeting delivery and in promoting intracellular gene transfer efficiency.

Methods: A folic acid-conjugated stearic acid-grafted chitosan (FA-CS-SA) micelle, synthesized by a 1-ethyl-3-(3-dimethylaminopropyl) carbodiimide-coupling reaction, was designed for specific receptor-mediated gene delivery.

Results: Due to the cationic properties of chitosan, the micelles could compact the plasmid DNA (pDNA) to form micelle/pDNA complexes nanoparticles. The particle size and zeta potential of the FA-CS-SA/pDNA complexes with different N/P ratios were $100-200 \mathrm{~nm}$ and -20 to $-10 \mathrm{mV}$, respectively. The DNase I protection assay indicated that the complexes can efficiently protect condensed DNA from enzymatic degradation by DNase I. A cytotoxicity study indicated that the micelles exhibited less toxicity in comparison with Lipofectamine ${ }^{\mathrm{TM}} 2000$. Using SKOV3 and A549 as model tumor cells, the cellular uptake of micelles was investigated.

Conclusion: It was found that cellular uptake of FA-CS-SA in SKOV3 cells with higher folate receptor expression was faster than that in A549 cells with a short incubation time. Luciferase assay and green fluorescent protein detection were used to confirm that FA-CS-SA could be an effective gene vector. Transfection efficiency of the FA-CS-SA/pDNA complexes in SKOV3 cells was enhanced up to 2.3-fold compared with that of the CS-SA/pDNA complexes. However, there was no significant difference between the transfection efficiencies of the two complexes in A549 cells. Importantly, the transfection efficiency of FA-CS-SA/pDNA decreased with free FA pretreatment in SKOV3 cells. It was concluded that the increase in transfection efficiency of the FA-CS-SA/pDNA complexes was attributed to folate receptor-mediated endocytosis.

Keywords: stearic acid-grafted chitosan, folic acid, polymeric micelles, folate receptor targeting, gene delivery

\section{Introduction}

Gene therapy is considered to be a powerful approach to the treatment of congenital and acquired diseases, by producing bioactive agents or stopping abnormal functioning of cells, such as genetic disorders or uncontrolled proliferation of cells. However, the lack of effective vectors is a major barrier to progress in human gene delivery. ${ }^{1}$ Virus vectors are very effective in terms of transfection efficiency, but their application in the human body is often frustrated by immunogenicity, potential infectivity, complicated production, and inflammation. ${ }^{2}$ The limitations of viral vectors have led to the evaluation and development of alternative vectors based on nonviral systems, such as liposomes ${ }^{3}$ 
and nanoparticles. ${ }^{4}$ Cationic nanoparticles have emerged as one of the most attractive carriers because of their ability to form complexes with negatively charged small interfering RNA (siRNA) and their high transfection efficiency. ${ }^{5}$ Chitosan has been considered to be a good gene carrier candidate, because it is known to be a biodegradable, biocompatible, low immunogenicity, and nontoxic material. ${ }^{6,7}$ Chitosan, as a cationic natural polysaccharide, can be complexed with negatively charged DNA by ionic interactions and protect DNA against DNase degradation. ${ }^{8,9}$ However, the low transfection efficiency and low specificity of chitosan must be overcome for its use in gene delivery. In addition, chitosan is poorly soluble because its amino groups are only partially protonated at physiological pH 7.4. Low molecular weight chitosan has been focused on for gene delivery systems because of its good solubility in physiological conditions, higher gene transfection, and more efficient enzymatic protection. ${ }^{10-12}$ Moreover, chitosan contains reactive amino and hydroxyl groups, thus many chitosan derivatives can be obtained by chemically altering its properties under mild reaction conditions. ${ }^{13,14}$ One approach to the improvement of transfection efficiency involves conjugating hydrophobic units with the polysaccharide backbone through amino groups or hydroxyl groups. ${ }^{15}$

An ideal gene carrier system should efficiently accumulate in specific target tissues with minimal toxicity to nontarget tissues. ${ }^{16}$ In order to increase the transfection efficiency of polymer/DNA complexes to tumor cells specifically, various targeting ligands, including antibodies, growth factors, peptides, and folate have been conjugated to several polymers. ${ }^{17-19}$ Folic acid (FA) has emerged as an optimal ligand for targeting the cell membrane and allows nanoparticle endocytosis via the folate receptor for higher transfection yields. At present, the folate receptor is a major focus in multiple experimental approaches to tumor-targeted therapy. The folate receptor is known to be overexpressed on many human cancer cell surfaces, such as the brain, kidney, lung, ovarian, and breast cancers, but is highly restricted in most normal tissues. ${ }^{20}$ When folate is covalently linked to a molecule via its carboxyl moiety, its affinity for its cell surface receptor $\left(\mathrm{K}_{\mathrm{d}}\right.$ about 10-9 $\mathrm{M}$ ) remains essentially unaltered. Some novel polymers have been synthesized, like folate-polylysine ${ }^{21}$ and folate-polyethylenimine, ${ }^{22,23}$ all of which specifically increase gene transfection efficiency in target cells compared with nontargeted polymers.

In our previous research, novel self-aggregated micelles were formed by an amphiphilic-grafted copolymer, ie, stearic acid-grafted chitosan copolymer (CS-SA). The micelles have a specific spatial structure with multiple hydrophobic domains near their surface, and thus achieve excellent internalization into cancer cells. ${ }^{24}$ They have been investigated in detail as a gene vector, but their transfection efficiency is not so well understood. Moreover, the cellular uptake of CS-SA/DNA complexes lacks specificity. Therefore, CS-SA copolymers were further modified with folic acid to increase gene transfection efficiency in target cells specifically, and then folate-conjugated CS-SA (FA-CS-SA) was synthesized, and its properties were investigated. A FA-CS-SA/pDNA complex was then prepared by ionic interaction, and physicochemical characterization of the complex was carried out. Cellular uptake in vitro was evaluated in SKOV3 cells (a folate receptor-overexpressing cell line) and A549 cells (a folate receptor-deficient cell line). In addition, the in vitro transfection efficiency of FA-CS-SA/pDNA complexes in terms of green fluorescent protein detection and the luciferase assay was also examined in the two cell lines.

\section{Materials and methods Materials}

Chitosan of low molecular weight $(5.0 \mathrm{kDa})$ was obtained by enzymatic degradation (molecular weight $450.0 \mathrm{kDa}, 95 \%$ deacetylated, Yuhuan Marine Biochemistry Co Ltd, Zhejiang, China). ${ }^{25}$ Stearic acid was obtained from Chemical Reagent Co Ltd (Shanghai, China). 1-ethyl-3-(3-dimethylaminopropyl)carbodiimide (EDC), 2,4,6-trinitrobenzene sulfonic acid (TNBS), and 3-(4,5-dimethylthiazol-2-yl)-2,5-diphenyltetrazolium bromide (MTT) were purchased from Sigma (St Louis, MO). Fetal bovine serum was purchased from Sijiqing Biologic Co Ltd (Zhejiang, China). Folic acid and fluorescein isothiocyanate (FITC) came from Sigma ( $\mathrm{St}$ Louis, MO), and Lipofectamine ${ }^{\mathrm{TM}} 2000$ was supplied by Invitrogen Corporation (Carlsbad, CA). DNase I, Dulbecco's Modified Eagle's Medium, and trypsin-ethylenediamine tetra-acetic acid were purchased from Gibco BRL (Gaithersberg, MD). Green fluorescent protein plasmid DNA (EGFP-C1) was donated by the first Affiliated Hospital of College of Medicine, Zhejiang University, Hangzhou, China. PGL-3, as the luciferase reporter gene, was kindly provided by the Institute of Life Science, Zhejiang University, Hangzhou, China. A luciferase assay kit and bicinchoninic acid protein assay kit were obtained from Beyotime Institute of Biotechnology, China. All other chemicals were of analytical grade and used without further purification.

\section{Synthesis of CS-SA}

CS-SA was synthesized via reaction of the carboxyl groups of SA with the amine groups of CS, catalyzed by EDC. In brief, $1.0 \mathrm{~g}$ of CS was dissolved in $120 \mathrm{~mL}$ of distilled water. SA $0.4 \mathrm{~g}$ with EDC (SA:EDC 1:10, mol:mol) was then dissolved in $80 \mathrm{~mL}$ of ethanol by sonication, followed 
by stirring in a water bath at $60^{\circ} \mathrm{C}$ for 1 hour. The mixture was added to the $\mathrm{CS}$ solution and the reaction was conducted with $400 \mathrm{rpm}$ for 5 hours at $80^{\circ} \mathrm{C}$ in a water bath. After the reaction mixture was cooled to room temperature, the synthesized product was dialyzed using a dialysis membrane (molecular weight cutoff $3.5 \mathrm{kDa}$, Spectrum Laboratories, Laguna Hills, CA) against distilled water for 48 hours in order to remove byproducts, followed by freeze drying. The lyophilized product was washed twice with ethanol to remove any unreacted SA.

\section{Synthesis of FA-CS-SA copolymer}

The free amino groups of CS-SA were conjugated with the carboxylic groups of FA in the presence of EDC. The carboxyl groups of FA were activated by EDC. Briefly, FA dissolved in dimethyl sulfoxide was reacted with 10 molar equivalents of EDC at room temperature for 1 hour under stirring. Thereafter, it was added to the CS-SA solution, and the resulting mixture was stirred at room temperature in the dark for 16 hours. The mixture was dialyzed against distilled water for 3 days and then lyophilized.

\section{Characterization of FA-CS-SA}

The critical micelle concentration of FA-CS-SA in aqueous medium was determined by fluorescence measurement using pyrene as a probe. ${ }^{26}$ Briefly, $6 \mathrm{mg}$ of pyrene was firstly dissolved in $50 \mathrm{~mL}$ of acetone as a pyrene stock solution. Before use, the pyrene stock solution was further diluted 100 -fold with acetone; $0.5 \mathrm{~mL}$ of pyrene solution with a concentration of $0.0012 \mathrm{mg} / \mathrm{mL}$ was transferred into test tubes, the acetone was then evaporated at $50^{\circ} \mathrm{C}$, and $5 \mathrm{~mL}$ of FA-CS-SA solution at different concentrations varying from $1.0 \times 10^{-3}$ to $1.0 \mathrm{mg} / \mathrm{mL}$ was added to the test tubes. The final concentration of pyrene was fixed at $6 \times 10^{-7} \mathrm{M}$. The fluorescence emission spectrum of pyrene was obtained using a fluorometer (F-2500, Hitachi Corporation, Osaka, Japan). The slit openings were set at $10 \mathrm{~nm}$ (excitation) and $2.5 \mathrm{~nm}$ (emission), and the excitation wavelength was $337 \mathrm{~nm}$. The intensity ratio of the first highest energy bands $(374 \mathrm{~nm})$ to the third $(385 \mathrm{~nm})$ in the pyrene emission spectra was then calculated.

The degrees of amino substitution of FA-CS-SA were determined by the TNBS method. ${ }^{27}$ Then $0.3 \mathrm{~mL}$ of FACS-SA solution at a concentration of $1 \mathrm{mg} / \mathrm{mL}$ was incubated with $2 \mathrm{~mL}$ of $4 \% \mathrm{NaHCO}_{3}$ and $2 \mathrm{~mL}$ of $0.1 \%$ TNBS at $37^{\circ} \mathrm{C}$ for 2 hours. The mixture was then added to $2 \mathrm{~mL}$ of $\mathrm{HCl}(2 \mathrm{~mol} / \mathrm{L})$ and measured at $344 \mathrm{~nm}$ by an ultraviolet spectrophotometer (TU-1800PC, Beijing Purkinje General Instrument Co Ltd, Beijing, China). The degrees of amino substitution for CS-SA were measured in a similar way to that described above. The FA to amino group molar ratio in the FA-CS-SA copolymer was estimated indirectly.

The size and zeta potential of the micelles with $1 \mathrm{mg} /$ $\mathrm{mL}$ of FA-CS-SA were measured by dynamic light scattering using a Zetasizer (3000 HS; Malvern Instruments Ltd, Worcester, UK). Each sample determination was done in triplicate.

\section{Preparation of FA-CS-SA/pDNA nanoparticles}

Briefly, FA-CS-SA was dissolved in deionized water at a concentration of $1 \mathrm{mg} / \mathrm{mL}$. The solution was then filtered using a $0.22 \mu \mathrm{m}$ Millipore filter. The plasmid DNA was diluted with phosphate-buffered saline to give a concentration of $0.5 \mathrm{mg} / \mathrm{mL}$. Nanoparticles were prepared by mixing pDNA with appropriate polymer solution at various charge ratios. The charge ratio (N/P) of FA-CS-SA/pDNA was expressed as the molar ratio of the primary amino group of FA-CS-SA to the phosphate groups of DNA. The complex was then vortexed for 30 seconds and incubated for 30 minutes at room temperature for complete complex formation.

\section{Determination of particle size and zeta potential}

Particle size and zeta potential of the FA-CS-SA/pDNA nanoparticles was determined by dynamic light scattering (Zetasizer 3000HS). Each sample determination was done in triplicate.

\section{Gel retardation assay}

The DNA binding ability of FA-CS-SA was evaluated by agarose gel electrophoresis. The FA-CS-SA/DNA nanoparticles containing $1.0 \mu \mathrm{g}$ of DNA were prepared at different N/P ratios $(0.1,0.2,0.4,0.8,1.6,3.2$, and 6.4 , respectively), by varying the concentration of FA-CS-SA. The nanoparticles and the naked plasmid were loaded into individual wells with $1.0 \%$ agarose gel in Tris-acetate-ethylenediamine tetraacetic acid buffer. The samples were run on the gel at 100 $\mathrm{V}$ for 40 minutes. Finally, the gel was stained with $0.5 \mathrm{mg} /$ $\mathrm{mL}$ ethidium bromide and photographed using an ultraviolet spectrophotometer (UV-1601; Shimadzu, Kyoto, Japan). As a control, the DNA binding ability of CS-SA was also evaluated by the same process as described for FA-CS-SA.

\section{DNase I protection assay}

Protection and release of DNA in FA-CS-SA/pDNA nanoparticles were carried out by electrophoresis according to the method described by Park et al. ${ }^{28}$ Briefly, $4 \mu \mathrm{L}$ of DNase I 
(2 units) or phosphate-buffered saline in DNase/ $\mathrm{Mg}^{2+}$ digestion buffer (50 mM, Tris-Cl, $\mathrm{pH} 7.6$ and $10 \mathrm{mM} \mathrm{MgCl}_{2}$ ) was added to $0.5 \mu \mathrm{g}$ of naked plasmid DNA or $4 \mu \mathrm{L}$ of nanoparticle solution and incubated at $37^{\circ} \mathrm{C}$ with shaking at $100 \mathrm{rpm}$ for 30 minutes. For DNase inactivation, all the samples were treated with $4 \mu \mathrm{L}$ of ethylenediamine tetra-acetic acid $(250 \mathrm{mM})$ for 10 minutes, and 1\% sodium dodecyl sulfate dissolved in 0.1 $\mathrm{M} \mathrm{NaOH}$ ( $\mathrm{pH}$ 7.2) was then added to a final volume of $18 \mu \mathrm{L}$. The final samples were further incubated for 2 hours to allow complete dissociation of complexes, and electrophoresis was performed with $1 \%$ agarose gel in Tris-acetate-ethylenediamine tetra-acetic running buffer for 1 hour at $100 \mathrm{~V}$.

\section{Cell culture}

SKOV3 and A549 cells were maintained in Dulbecco's Modified Eagle's Medium or RPMI 1640 media supplemented with $10 \%$ fetal bovine serum, penicillin $100 \mathrm{U} / \mathrm{mL}$, streptomycin $100 \mathrm{U} / \mathrm{mL}$. Both cell lines were cultured at $37^{\circ} \mathrm{C}$ in a humidified $5 \% \mathrm{CO}_{2}$ atmosphere.

\section{Cellular uptake studies}

In order to investigate cellular uptake, FA-CS-SA copolymer was labeled with FITC via reaction of the amino groups of chitosan and the isothiocyanate groups of FITC. The molar ratio of FA-CS-SA to FITC was fixed at 2:1. The solution was then stirred for 12 hours with $400 \mathrm{rpm}$ at room temperature in aphotic environment. The reaction product was dialyzed against distilled water using a dialysis membrane (molecular weight cutoff $3.5 \mathrm{kDa}$, Spectrum Laboratories, Laguna Hills, CA) for 24 hours to remove the unreacted FITC. SKOV3 and A549 cells were seeded at $3 \times 10^{4}$ cells/well in a 24-well plate, and grown for 24 hours. After removing the growth medium, $1.0 \mathrm{~mL}$ RPMI 1640 medium containing $100 \mu \mathrm{g}$ FITC-labeled FA-CS-SA was added. The cells were further incubated for 1, 2, 3, 6, 12, and 24 hours, respectively. The cells were then washed twice with phosphate-buffered saline ( $\mathrm{pH} 7.4)$ and directly viewed under a fluorescence microscope (Leica DM4000 B; Leica, Solms, Germany). The fluorescence images were obtained at $20 \times$ magnification. As a control, FITC-labeled CS-SA was used to observe cellular uptake as described above.

\section{In vitro cytotoxicity assay}

The cytotoxicity of the copolymers was measured by MTT assay. SKOV3 and A549 cells were seeded at a density of $1 \times 10^{4}$ cells/well in $200 \mu \mathrm{L}$ complete medium in $96-w e l l$ plates and incubated for 24 hours at $37^{\circ} \mathrm{C}$. The growth medium was then removed and replaced with fresh medium containing copolymer (CS-SA or FA-CS-SA) or Lipofectamine 2000. The cells were then incubated further for 48 hours. After incubation, $20 \mu \mathrm{L}$ of MTT $(5.0 \mathrm{mg} / \mathrm{mL})$ was added and incubated for 4 hours under normal growing conditions. After the medium with the unreacted MTT was removed, $200 \mu \mathrm{L}$ of dimethyl sulfoxide was added to each well. The well plates were shaken for 20 minutes and the absorbance of formazan product was measured at $570 \mathrm{~nm}$ in a microplate reader (Model 680; BioRad, Mountain View, CA). Cells without polymers were used as a control.

\section{In vitro transfection studies}

SKOV3 and A549 cells were seeded in 24-well plates at a density of $1 \times 10^{5}$ cells per well in $1 \mathrm{~mL}$ of complete medium and incubated for 24 hours prior to transfection. The media was then replaced with fresh growth medium in each well. pDNA was diluted with phosphate-buffered saline ( $\mathrm{pH} 7.4$ ) to $0.5 \mathrm{mg} /$ $\mathrm{mL}$, and then added to an appropriate amount of the copolymer in the same buffer with an equal volume to obtain the desired $\mathrm{N} / \mathrm{P}$ ratios. The complexes were mixed using a vortex mixer for 30 seconds and then allowed to stand for 30 minutes at room temperature. Complexes containing $2 \mu \mathrm{g}$ EGFP plasmid were subsequently added to the wells and incubated with the cells initially for 6 hours. The medium was then replaced with $1 \mathrm{~mL}$ of fresh complete medium, and the cells were incubated for an additional $24-72$ hours at $37^{\circ} \mathrm{C}$. As a positive control, transfection with Lipofectamine 2000/DNA complexes was performed according to the manufacturer's protocol. Briefly, Lipofectamine 2000/DNA complexes were incubated with cells in $1 \mathrm{~mL}$ of serum-free medium for 6 hours, and further incubated with fresh complete medium for 24-72 hours at $37^{\circ} \mathrm{C}$. Naked DNA was used on the cell cultures and examined as described above. All transfection experiments were performed in triplicate. The cells were transferred to an inverted fluorescence microscope (Leica DMI 4000B) for imaging.

To evaluate transfection efficiency, FA-CS-SA/DNA complexes ( $2 \mu \mathrm{g}$ pGL3 plasmid) were prepared for transfection into SKOV3 and A549 cells. The transfection procedure was carried out using methods similar to those described above. Transfection efficiency was detected by assay of luciferase activity. After incubation for 72 hours with the cells, the growth medium was removed, and the cells were lysed with cell lysate buffer (Beyotime) and shaken for 30 minutes at room temperature. The luciferase assay was carried out according to the manufacturer's instructions. Relative light units were measured using a luminometer (Turner Designs Luminometer Model TD-20/20, Promega), and the protein assay was performed using a bicinchoninic acid protein assay reagent kit (Beyotime). The final results were reported in terms of relative light units/mg cellular protein. All transfection experiments were performed in triplicate. 


\section{FA competition studies}

SKOV3 and A549 cells were cultured in the same conditions as those used for the transfection tests. The cells were seeded in 24 -well plates at $1 \times 10^{5}$ cells/well and incubated for 24 hours. One hour before the transfection test, the medium was replaced with RPMI 1640 containing FA $5.0 \mathrm{mM}$. The cells were then treated with FA-CS-SA/pDNA complex containing $2 \mu \mathrm{g}$ of plasmid DNA at predetermined N/P ratios for 6 hours at $37^{\circ} \mathrm{C}$ in $5 \% \mathrm{CO}_{2}$. After an exchange of fresh medium, the cells were further incubated for 24-72 hours at $37^{\circ} \mathrm{C}$. Transfection efficiency was assessed using the same method as described for the luciferase assay.

\section{Results and discussion Synthesis of FA-CS-SA}

CS-SA was synthesized via reaction of the amino groups of CS with the carboxyl groups of SA in the presence of EDC. The degree of amino substitution in the prepared CS-SA was about $19.9 \%$, as determined by the TNBS method. CS-SA micelles were easily prepared by dispersing CS-SA in distilled water under ultrasound, due to the inherent selfaggregation of CS-FA in an aqueous environment. FA-CS-SA could be synthesized by chemically linking FA to CS-SA via the reaction of the carboxyl groups of FA and the amino groups on the CS-SA micelle surface, in the presence of EDC. The degree of amino substitution of FA-CS-SA was $25.2 \%$, as determined by the TNBS methods. The molar ratio of folic acid/ $\mathrm{NH}_{2}$ in FA-CS-SA copolymer was $5.3 \%$.

\section{Characteristics of FA-CS-SA}

The aggregation behavior of FA-CS-SA and CS-SA in aqueous media was measured by fluorometry using pyrene as a fluorescent probe. The critical micelle concentration refers to the threshold self-aggregation concentration of amphiphilic polymer. The $\mathrm{I}_{1} / \mathrm{I}_{3}$ ratio, ie, the first to third highest energy bands in the pyrene emission spectra $\left(I_{1}, e m=374 \mathrm{~nm} ; \mathrm{I}_{3}, \mathrm{em}=385 \mathrm{~nm}\right)$ was used to determined the critical micelle concentration value of the polymer. As the concentration increased to form micelles, the total emission fluorescence intensity increased, especially the intensity of the third highest energy band. As a result, the fluorescence intensity ratio of $\mathrm{I}_{1} / \mathrm{I}_{3}$ decreased. Variation in the fluorescence intensity ratio of $I_{1} / I_{3}$ against the logarithm of FA-CS-SA and CS-SA concentration is shown in Figure 1. The critical micelle concentration values of FACS-SA and CS-SA in distilled water were determined to be about $105 \mu \mathrm{g} / \mathrm{mL}$ and $147 \mu \mathrm{g} / \mathrm{mL}$, respectively, which showed that the modification of FA improved the ability of CS-SA to self-assemble in water.

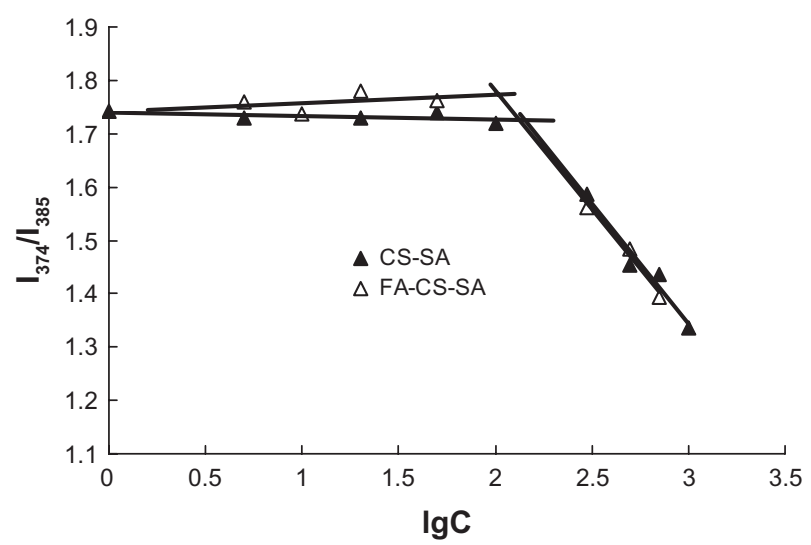

Figure I Variation of intensity ratio $\left(I_{1} / I_{3}\right)$ vs the logarithm of concentration of CSSA and FA-CS-SA. Unit of concentration was $\mu \mathrm{g} / \mathrm{mL}$.

Abbreviations: CS-SA, stearic acid-grafted chitosan copolymer; FA-CS-SA, folic acid-conjugated stearic acid-grafted chitosan copolymer.

The distributions of hydrodynamic diameter and zeta potential of FA-CS-SA micelles with $1 \mathrm{mg} / \mathrm{mL}$ of FA-CS-SA are shown in Figure 2. The average hydrodynamic diameter and zeta potential of the FA-CS-SA micelles was $51.1 \mathrm{~nm}$ and $13.7 \pm 4.7 \mathrm{mV}$, respectively.

\section{Characteristics of FA-CS-SA/DNA nanoparticles}

Due to its positive charge, the FA-CS-SA micelle was used to condense DNA, forming FA-CS-SA/DNA complex nanoparticles. The FA-CS-SA/DNA complex nanoparticles with N/P ratios from 0.25 to 20 were prepared by mixing the appropriate volume of FA-CS-SA micelle solution and DNA solution. The size and zeta potential of the nanoparticle complexes were measured using a dynamic light scattering technique. Figure 3 showed the Z-average diameter and zeta potential of FA-CS-SA/DNA complexes at various charge ratios. The size of the FA-CS-SA/DNA complexes increased as the N/P ratio increased from 0.25 to 1 . When the $\mathrm{N} / \mathrm{P}$ ratio was about 1, precipitation occurred and the size increased to microlevels due to the charge neutrality. Again, on increasing the N/P ratio, the size was found to decrease below $200 \mathrm{~nm}$. The zeta potential of the FA-CS-SA/DNA complexes (Figure 3) showed that the zeta potential changed from negative to positive when the N/P ratio increased from 0.5 to 20 . The complexes had the highest zeta potential when the N/P ratio was about 2. With increasing N/P ratios, the zeta potential was found to approach a plateau, with no significant variation in the zeta potential.

In order to determine the ability of FA-CS-SA to condense DNA, solutions of FA-CS-SA/DNA with different N/P ratios were electrophoresed on agarose gel containing ethidium bromide. Complete retardation of FA-CS-SA/DNA complexes 
A

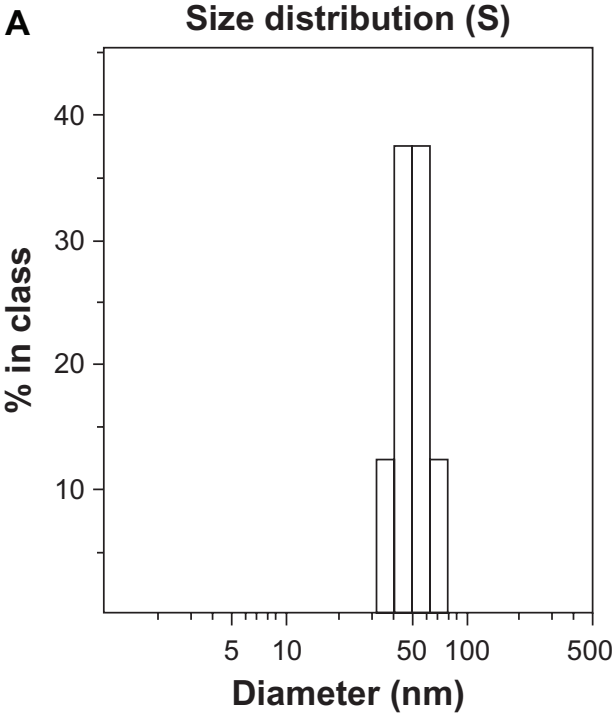

B

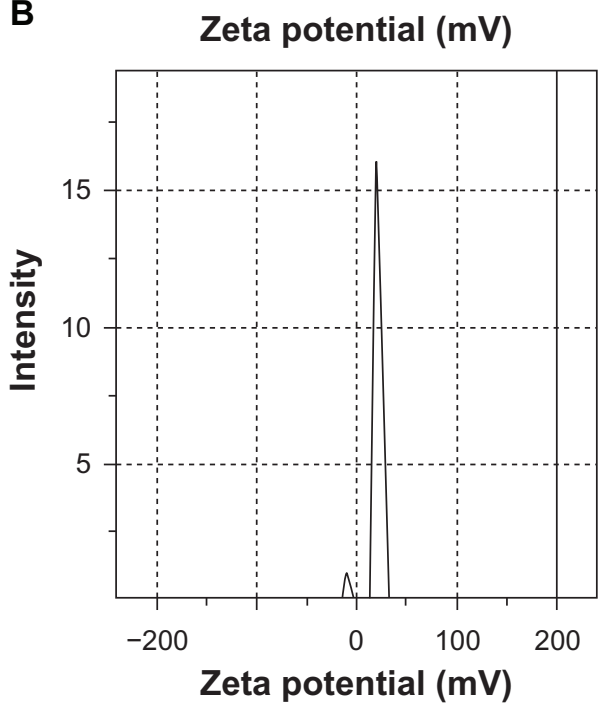

Figure 2 (A) Average size distribution and (B) zeta potential of folic acid-conjugated stearic acid-grafted chitosan copolymer micelles at a concentration of I mg/mL.

was observed at N/P ratios of 0.8 and onwards (Figure 4B). As a control, the migration of CS-SA/DNA complexes was performed when the N/P ratio was above 0.8 (Figure $4 A$ ). The results indicate that FA-CS-SA had a stronger ability than CS-SA to condense DNA into nanoparticles.
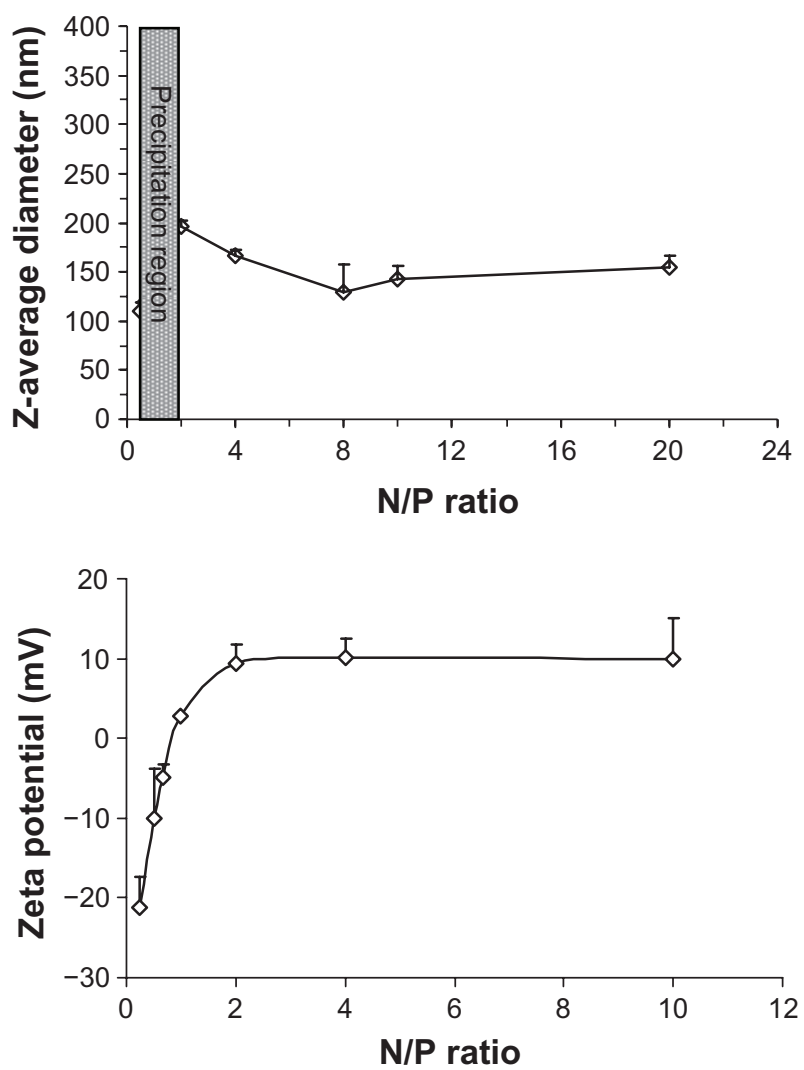

Figure 3 Variations in Z-average diameter and zeta potential of folic acid-conjugated stearic acid-grafted chitosan copolymer/plasmid DNA nanoparticle complexes versus $\mathrm{N} / \mathrm{P}$ ratio.

\section{DNase I protection assay}

Protection of plasmid DNA from nucleases is a primary requisite for efficient gene delivery in vivo and in vitro. ${ }^{29} \mathrm{As}$ shown in Figure 5, dissociation of DNA from copolymers was achieved although some still remained as a complex. Unlike the naked plasmid DNA control, the copolymer protected DNA. When naked pDNA was treated with two units of DNase I, it was completely degraded without any smear (lane 2). After adding 1\% sodium dodecyl sulfate, the pDNA could be released from the FA-CSO-SA/pDNA complexes (lane 3 and lane 4). The Figure shows that at the

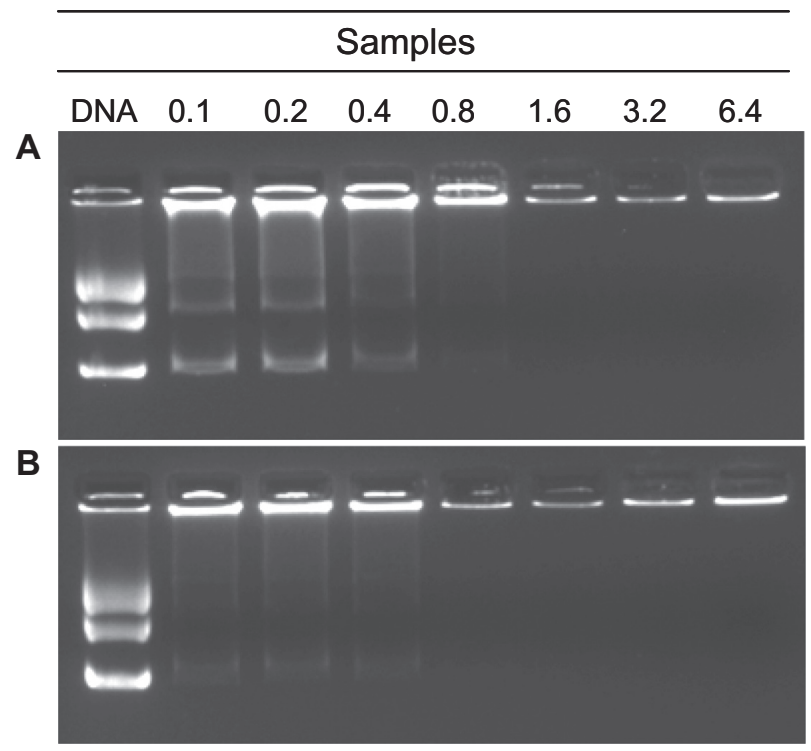

Figure $4 \mathrm{Gel}$ retarding analysis of (A) stearic acid-grafted chitosan copolymer/plasmid DNA and (B) folic acid-conjugated stearic acid-grafted chitosan copolymer/plasmid DNA complex nanoparticles. Lane I represents naked DNA; lanes 2-8 represent complex nanoparticles with N/P ratios of $0.1,0.2,0.4,0.8,1.6,3.2$, and 6.4 , respectively. 


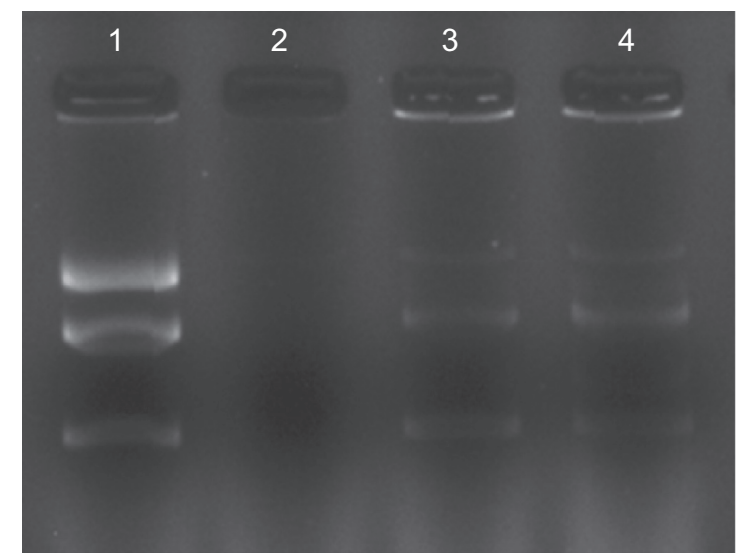

Figure 5 Protection and release assay of DNA. Lane I represents naked DNA(pEGFP-CI); lane 2 represents naked DNA treated with DNase I; lane 3 represents folic acid-conjugated stearic acid-grafted chitosan copolymer/DNA complex; lane 4 represents folic acid-conjugated stearic acid-grafted chitosan copolymer/DNA complex treated with DNase I.

same concentration of DNase I, the pDNA was protected from degradation by FA-CSO-SA micelles effectively when the $\mathrm{N} / \mathrm{P}$ ratio was 2 .

\section{Cellular uptake}

It has been demonstrated that folate-mediated biomolecular uptake is roughly proportional to the folate receptor density on the target cell membrane. To investigate the targeting efficiency of FA-CS-SA micelles, the cellular uptake of FA-CS-SA labeled with FITC was evaluated in SKOV3 cells and visualized using fluorescence microscopy (Figure 6A). After 0.5 hours of incubation, FITC-labeled FA-CS-SA was distributed in the SKOV3 cells, with green fluorescence throughout the entire cytoplasm. However, CS-SA was detected only as spot-like fluorescence. With a longer incubation time, fluorescence was enhanced, with a significant difference in fluorescence intensity between FA-CS-SA and CS-SA in the SKOV3 cells.

When the CS-SA copolymers were conjugated with FA, cellular uptake was mainly mediated by FA during a short incubation time, which indicated that shortening the incubation time was helpful to see the difference in cellular uptake between the two micelles. After 8 hours of incubation, with further enhanced fluorescence of CS-SA, the difference
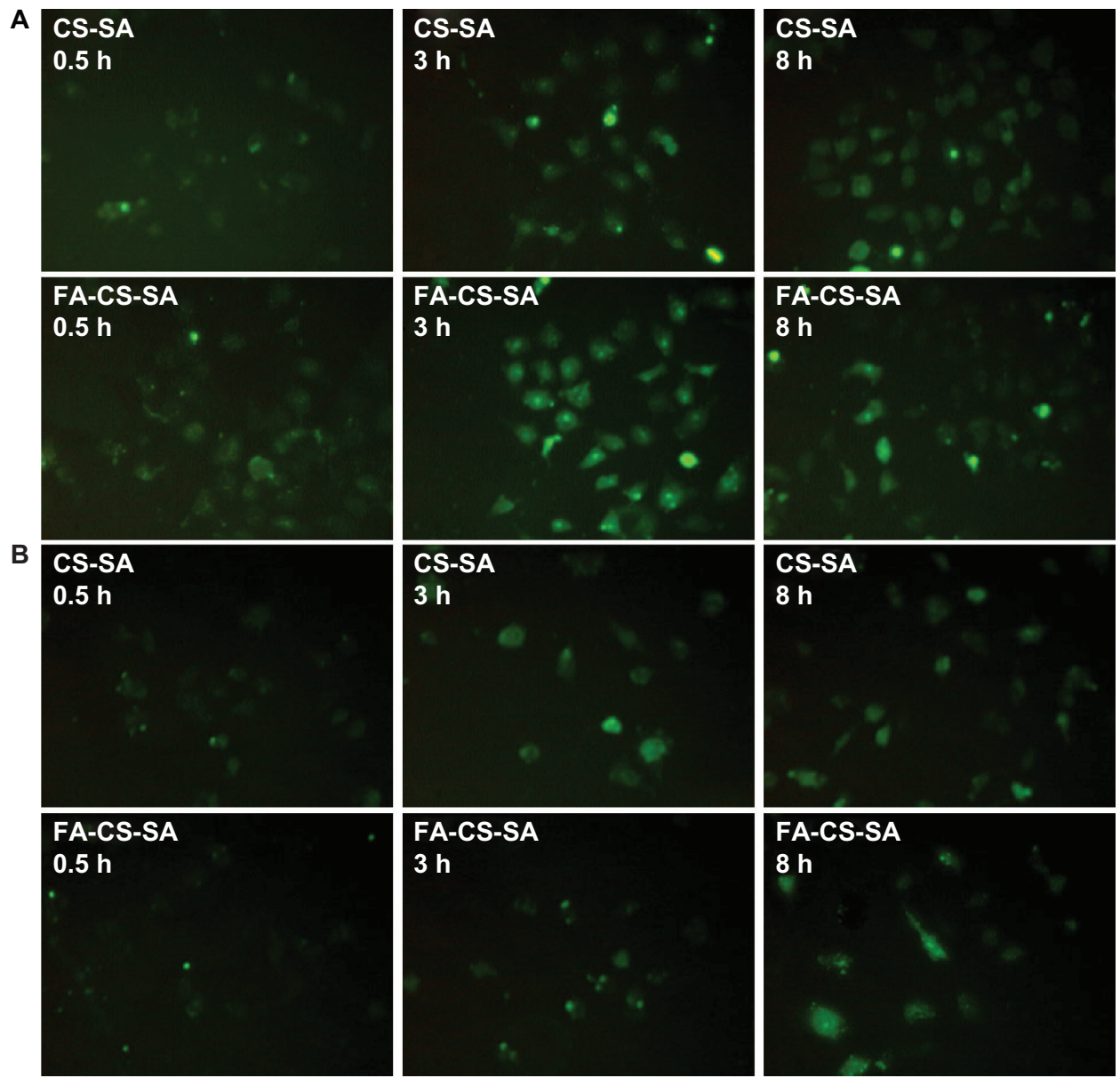

Figure 6 Fluorescence images of (A) SKOV3 cells and (B) A549 cells incubated with FITC-labeled stearic acid-grafted chitosan copolymer and folic acid-conjugated stearic acid-grafted chitosan copolymer for $0.5,3.0$, and 8.0 hours.

Abbreviations: CS-SA, stearic acid-grafted chitosan copolymer; FA-CS-SA, folic acid-conjugated stearic acid-grafted chitosan copolymer. 
between the two micelles disappeared. This is because of the increasing concentration of micelle complexes in the cells, with the internalization ability attributed to the cellular components and their special spatial structure. ${ }^{30}$

To verify further the effect of the folate receptor on the intracellular uptake of FA-CS-SA, A549 cells were used as a negative control for the intracellular uptake experiment. Figure 6B showed that there was no significant difference between intracellular uptake of FA-CS-SA and that of CS-SA, regardless of the incubation time.

\section{Evaluation of cytotoxicity}

The cytotoxicity of the FA-CS-SA and CS-SA copolymers were estimated by MTT assay. The $\mathrm{IC}_{50}$ value of CS-SA and FA-CS-SA were higher than that of Lipofectamine 2000, suggesting that both CS-SA and FA-CS-SA had lower cytotoxicity compared with Lipofectamine 2000 regardless of the cell lines used, and the difference in cytotoxicity between FA-CS-SA and CS-SA was not significant. As Figure 7 shows, the $\mathrm{IC}_{50}$ values of the CS-SA and FA-CS-SA micelles against SKOV3 cells were $115.15 \mu \mathrm{g} / \mathrm{mL}$ and $217.18 \mu \mathrm{g} / \mathrm{mL}$, respectively, and against A549 cells were $201.91 \mu \mathrm{g} / \mathrm{mL}$ and $298.46 \mu \mathrm{g} / \mathrm{mL}$, while the $\mathrm{IC}_{50}$ values of Lipofectamine 2000 were about $9.91 \mu \mathrm{g} / \mathrm{mL}$ and $29.50 \mu \mathrm{g} /$ $\mathrm{mL}$. The cytotoxicity of CS-SA and FA-CS-SA micelles at a higher concentration might originate from the large amounts of exogenous substances internalized into the cells. Thereafter, a lower concentration of micelles was used. The highest concentration used in gene delivery was $40 \mathrm{mg} / \mathrm{mL}$ when the N/P was 20, which was markedly lower than that of the $\mathrm{IC}_{50}$ value.

\section{Transfection experiments}

SKOV3 cells expressing folate receptors were used to determine whether gene delivery with FA-CS-SA is folate receptor-mediated. Transfection efficiencies of the FACS-SA/DNA and CS-SA/DNA complexes at different N/P ratios varying from 1 to 20 were determined in our preliminary experiments. The maximum transfection efficiency of the FA-CS-SA/DNA complex was observed at an N/P ratio of 2 , and this tended to decrease with further increases in the $\mathrm{N} / \mathrm{P}$ ratio. The transfection efficiency of the copolymer/DNA complexes was visualized by fluorescence microscopy. The images in Figure 8 show that SKOV3 cells were transfected with copolymer/pEGFP-C1 complexes at optimal N/P ratios. The transfection efficiency of FA-CS-SA/DNA could not reach the high level of Lipofectamine 2000, but it was much higher than that of CS-SA/DNA.
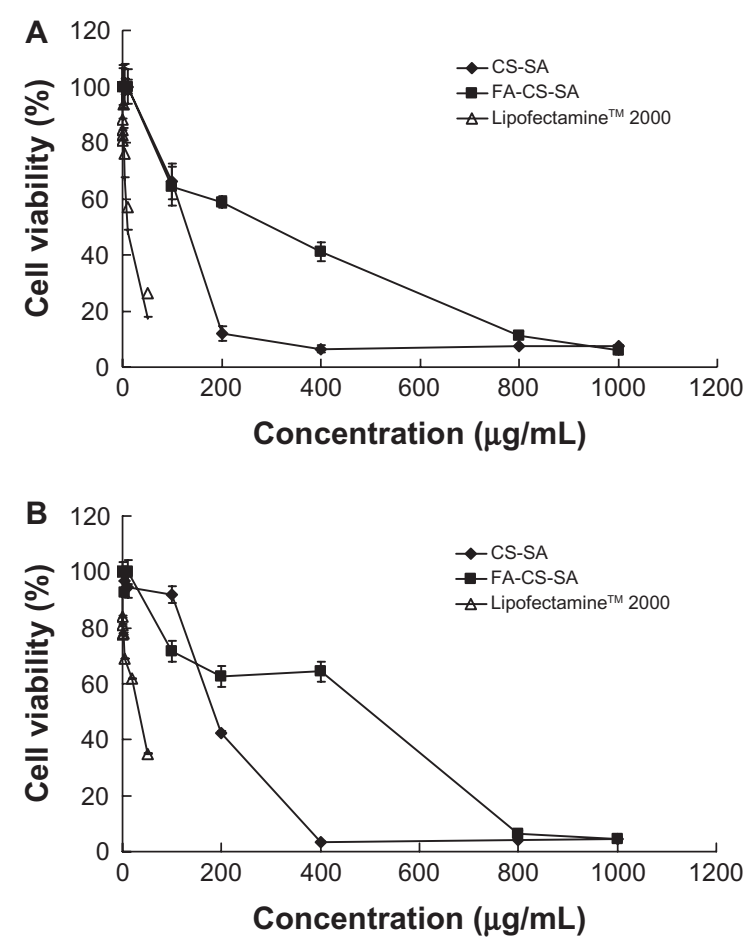

Figure 7 Cytotoxicity of folic acid-conjugated stearic acid-grafted chitosan copolymer and stearic acid-grafted chitosan copolymer in comparison with Lipofectamine ${ }^{\mathrm{TM}}$ 2000 in (A) SKOV3 cells and (B) A549 cells.

Abbreviations: CS-SA, stearic acid-grafted chitosan copolymer; FA-CS-SA, folic acid-conjugated stearic acid-grafted chitosan copolymer.

To quantify transfection efficiency, the plasmid pGL-3 was used as the luciferase reporter gene, and a luciferase expression assay induced by the copolymers/pGL-3 complexes was carried out. Figure 9A shows the transfection efficiencies of FA-CS-SA/DNA, CS-SA/DNA, and Lipofectamine 2000/ DNA complexes at different N/P ratios in terms of luciferase activity of the protein expressed. Figure 9B showed the
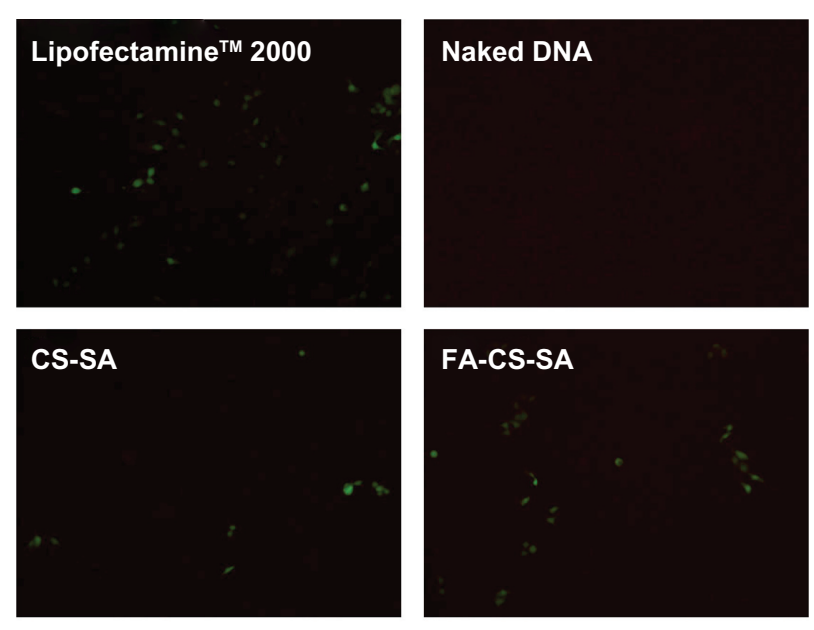

Figure 8 Green fluorescent protein detection of transfected SKOV3 cells observed by inverted microscopy.

Abbreviations: CS-SA, stearic acid-grafted chitosan copolymer; FA-CS-SA, folic acid-conjugated stearic acid-grafted chitosan copolymer. 

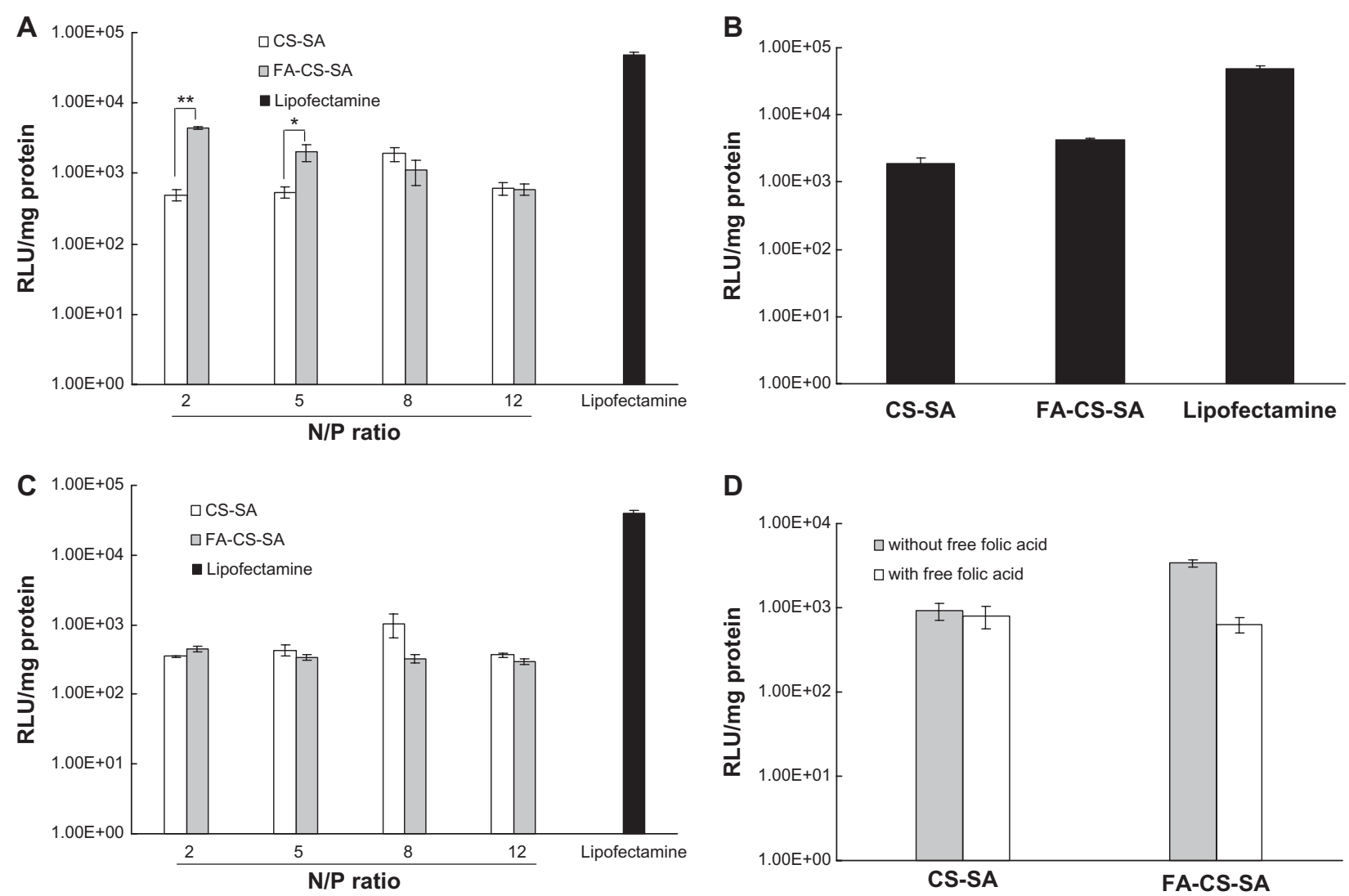

Figure 9 (A) Transfection efficiency of folic acid-conjugated stearic acid-grafted chitosan copolymer/DNA and stearic acid-grafted chitosan copolymer/DNA complexes at various N/P ratios in SKOV3 cells. (B) Transfection efficiency of folic acid-conjugated stearic acid-grafted chitosan copolymer DNA and stearic acid-grafted chitosan copolymer/DNA complexes at functional N/P ratios in SKOV3 cells. (C) Transfection efficiency of folic acid-conjugated stearic acidgrafted chitosan copolymer/DNA and stearic acid-grafted chitosan copolymer/DNA complexes at various N/P ratios in A549 cells. (D) Competitive assay of folic acid-conjugated stearic acid-grafted chitosan copolymer/DNA and stearic acid-grafted chitosan copolymer/DNA complexes by adding free folic acid 5.0 mM. Notes: Values are means \pm standard deviation. $* P<0.05$ and $* * P<0.01$.

Abbreviations: CS-SA, stearic acid-grafted chitosan copolymer; FA-CS-SA, folic acid-conjugated stearic acid-grafted chitosan copolymer.

transfection efficiencies of FA-CS-SA/DNA and CS-SA/ DNA complexes at optimal N/P ratios. It was found that the transfection efficiency of FA-CS-SA/DNA complexes was 2.3-fold higher than that of the CS-SA/DNA complexes.

In order to demonstrate further the effect of the folate receptor on the transfection efficiencies of FA-CS-SA/DNA complexes, a transfection experiment was conducted using A549 cells deficient in the folate receptor. Figure 9C shows that the two complexes exhibited no difference in transfection efficiency in A549 cells, indicating that the folate ligand on FA-CS-SA plays a significant role in folate receptor recognition and enhanced transfection efficiency in SKOV3 cells.

From Figure 9D, it can be observed that, due to the competitive displacement of free FA, the transfection efficiency of the FA-CS-SA/DNA complexes in SKOV3 cells was greatly reduced (by 5.4-fold) in the presence of excess FA (5.0 mM) compared with the medium free of FA, whereas the free FA in the medium did not affect the transfection efficiency of the CS-SA/DNA complexes. The results suggest that free FA molecules could prevent cellular uptake of the complexes by competitive binding to folate receptors on the cell surface. In other words, conjugation of FA indeed improved the transfection efficiency of FA-CS-SA for gene delivery to folate receptor-positive cells.

\section{Conclusion}

FA-CS-SA was synthesized in this study by the reaction between the carboxyl groups of folate and the amine groups of CS-SA in the presence of EDC, which could self-aggregate to form micelle-like structures in aqueous solution. FA-CS-SA showed a good ability to form complexes with plasmid DNA and could efficiently protect condensed DNA from enzymatic degradation by DNase I. It had much lower cytotoxicity compared with Lipofectamine 2000. Folate conjugation increased the intracellular uptake of FA-CS-SA in SKOV3 cells via folate receptor-mediated endocytosis at shorter incubation times. The FA-CS-SA/DNA complexes displayed higher transfection efficiency at certain $\mathrm{N} / \mathrm{P}$ ratios in comparison with 
that of CS-SA/DNA complexes in SKOV3 cells, whereas no difference in folate receptor-negative A549 cells was found. The results suggest that FA-CS-SA has the potential to be a safe and effective nonviral vector for gene delivery.

\section{Acknowledgments}

We appreciate the financial support of the National Nature Science Foundation of China (30873174 and 81072583) and the Nature Science Foundation of Zhejiang Province (z207489 and Y2090336).

\section{Disclosure}

The authors report no conflicts of interest in this work.

\section{References}

1. Kabanov AV, Kabanov VA. DNA complexes with polycations for the delivery of genetic material into cells. Bioconjug Chem. 1995;6:7-20.

2. Smith A. Viral vectors in gene therapy. Annu Rev Microbiol. 1995;49: 807-838.

3. Bedi D, Musacchio T, Fagbohun OA, et al. Delivery of siRNA into breast cancer cells via phage fusion protein-targeted liposomes. Nanomedicine. 2011;7:315-323.

4. Chen XA, Zhang LJ, He ZJ, et al. Plasmid-encapsulated polyethylene glycol-grafted polyethylenimine nanoparticles for gene delivery into rat mesenchymal stem cells. Int J Nanomedicine. 2011;6:843-853.

5. Gao Y, Liu XL, Li XR. Research progress on siRNA delivery with nonviral carriers. Int J Nanomedicine. 2011;6:1017-1025.

6. Borchard G. Chitosans for gene delivery. Adv Drug Deliv Rev. 2001;52:145-150.

7. Mansouri S, Lavigne P, Corsi K. Chitosan-DNA nanoparticles as nonviral vectors in gene therapy: strategies to improve transfection efficacy. Eur J Pharm Biopharm. 2004;57:1-8.

8. Cui Z, Mumper RJ. Chitosan-based nanoparticles for topical genetic immunization. J Control Release. 2001;75:409-419.

9. Illum L, Jabbal-Gill I, Hinchcliffe M, Fisher AN, Davis SS. Chitosan as a novel nasal delivery system for vaccines. Adv Drug Deliv Rev. 2001;51:81-96.

10. Lee M, Nah JW, Kwon Y, Koh JJ, Ko KS, Kim SW. Water-soluble and low molecular weight chitosan-based plasmid DNA delivery. Pharm Res. 2001;18:427-431.

11. Köping-Höggård M, Vårum KM, Issa M, et al. Improved chitosanmediated gene delivery based on easily dissociated chitosan polyplexes of highly defined chitosan oligomers. Gene Ther. 2004;11:1441-1452.

12. Peng J, Xing X, Wang K, Tan W, He X, Huang S. Influence of anions on the formation and properties of chitosan-DNA nanoparticles. J Nanosci Nanotechnol. 2005;5:713-717.

13. Yoksan R, Matsusaki M, Akashi M, Chirachanchai S. Controlled hydrophobic/hydrophilic chitosan: colloidal phenomena and nanosphere formation. Colloid Polym Sci. 2004;282:337-342.
14. Kim KY, Kwon SL, Park JH, Chung H, Jeong SY, Kwon IC. Physicochemical characterizations of self-assembled nanoparticles of glycol chitosan-deoxycholic acid conjugates. Biomacromolecules. 2005;6:1154-1158.

15. Kurisawa M, Yokoyama M, Okano T. Transfection efficiency increases by incorporating hydrophobic monomer units into polymeric gene carriers. J Control Release. 2000;68:1-8.

16. Luten J, Steenbergen MJ, van Lok MC, et al. Degradable PEGfolate coated poly(DMAEA-co-BA)phosphazene-based polyplexes exhibit receptor-specific gene expression. Eur J Pharm Sci. 2008;33:241-251.

17. Lee H, Kim TH, Park TG. A receptor-mediated gene delivery system using streptavidin and biotin-derivatized, pegylated epidermal growth factor. J Control Release. 2002;83:109-119.

18. Hashimoto M, Morimoto M, Saimoto H, Sato T. Lactosylated chitosan for DNA delivery into hepatocytes: the effect of lactosylation on the physicochemical properties and intracellular trafficking of pDNA/ chitosan complexes. Bioconjug Chem. 2006;17:309-316.

19. Kim Y, Choi JY, Yoo M, et al. Receptor-mediated gene delivery by folate-PEG-baculovirus in vitro. J Biotechnol. 2007;131:353-361.

20. Sudimack J, Lee RJ. Targeted drug delivery via the folate receptor. $A d v$ Drug Deliv Rev. 2000;41:147-162.

21. Mislick KA, Baldeschwieler JD, Kayyem JF, Meade TJ. Transfection of folate-polylysine DNA complexes: evidence for lysosomal delivery. Bioconjug Chem. 1995;6:512-515.

22. Guo WJ, Lee RJ. Receptor-targeted gene delivery via folate-conjugated polyethyleneimine. AAPS Pharmsci. 1999;1:E19.

23. Guo WJ, Lee RJ. Efficient gene delivery via non-covalent complexes of folic acid and polyethylenimine. J Control Release. 2001;77:131-138.

24. You J, Hu FQ, Du YZ, Yuan H. Polymeric micelles with glycolipidlike structure and multiple hydrophobic domains for mediating-target delivery of paclitaxel. Biomacromolecules. 2007;8:2450-2456.

25. Hu FQ, Zhao MD, Yuan H, You J, Du YZ, Zeng S. A novel chitosan oligosaccharide-stearic acid micelles for gene delivery: properties and in vitro transfection studies. Int J Pharm. 2006;315:158-166.

26. Moromoto H, Hashidzume A, Morishima Y. Fluorescence studies of associative behavior of cationic surfactant moieties covalently linked to poly(acrylamide) at the surfactant head or tail. Polymer. 2003;44:943-952.

27. Schnurch AB, Krajicek ME. Mucoadhesive polymers as platforms for peroral peptide delivery and absorption: synthesis and evaluation of different chitosan-EDTA conjugates. J Control Release. 1998;50:215-223.

28. Park MR, Han KO, Han IK, et al. Degradable polyethyleniminealt-poly(ethylene glycol) copolymers as novel gene carriers. J Control Release. 2005;105:367-380.

29. Katayose S, Kataoka K. Remarkable increase in nuclease resistance of plasmid DNA through supramolecular assembly assembly with poly(ethylene glycol)-poly(L-lysine) block copolymer. J Pharm Sci. 1998;87:160-163.

30. You J, Li X, Cui FD, Du YZ, Yuan H, Hu FQ. Folate-conjugated polymer micelles for active targeting to cancer cells: preparation, in vitro evaluation of targeting ability and cytotoxicity. Nanotechnology. 2008;19:1-9.
International Journal of Nanomedicine

\section{Publish your work in this journal}

The International Journal of Nanomedicine is an international, peerreviewed journal focusing on the application of nanotechnology in diagnostics, therapeutics, and drug delivery systems throughout the biomedical field. This journal is indexed on PubMed Central, MedLine, CAS, SciSearch ${ }^{\circledR}$, Current Contents ${ }^{\circledR} /$ Clinical Medicine,

\section{Dovepress}

Journal Citation Reports/Science Edition, EMBase, Scopus and the Elsevier Bibliographic databases. The manuscript management system is completely online and includes a very quick and fair peer-review system, which is all easy to use. Visit http://www.dovepress.com/ testimonials.php to read real quotes from published authors. 